\title{
Correction to: Sex-specific risks of death in patients hospitalized for hyponatremia: a population-based study
}

\author{
Buster Mannheimer ${ }^{1} \cdot$ Jakob Skov $^{2} \cdot$ Henrik Falhammar ${ }^{2,3} \cdot J^{\prime}$ an Calissendorff ${ }^{2,3} \cdot$ Jonatan D. Lindh $^{4}$. \\ David Nathanson (D) ${ }^{1,5}$
}

Published online: 24 November 2020

(c) Springer Science+Business Media, LLC, part of Springer Nature 2020

\section{Correction to: Endocrine \\ https://doi.org/10.1007/s12020-019-02073-x}

The original version of this article unfortunately contained some errors in the dataset. Instead of only including patients with a primary diagnosis of hyponatremia some cases with hyponatremia as a secondary diagnosis had been included. When corrected, the number of cases admitted with a primary diagnosis of hyponatremia were 11,213 instead of 14,359 as reported in the manuscript, and thus the number of matched controls became 44,801 instead of 57,382. The second error relates to the index date which is in fact the discharge date, not the admission date as initially thought.

However, these errors have had a marginal impact on the results, with magnitudes and direction of associations for all adjusted hazard ratios much the same after correction. The corrected (italic) and incorrect (bold) hazard ratios are presented in the table below to demonstrate the changes in estimates:

\begin{tabular}{lll}
\hline & $\begin{array}{l}\text { Corrected hazard } \\
\text { ratios }(95 \%)\end{array}$ & $\begin{array}{l}\text { Incorrect hazard } \\
\text { ratios }(95 \%)\end{array}$ \\
\hline $\begin{array}{l}\text { Fig. 1 } \\
\text { All individuals }\end{array}$ & $6.0(4.6-7.7)$ & $\mathbf{5 . 5}(\mathbf{4 . 4 - 7 . 0 )}$ \\
$\begin{array}{l}\text { Fig. 2 } \\
\text { Individuals without } \\
\text { previous comorbidity }\end{array}$ & $8.8(4.2-18.1)$ & $\mathbf{6 . 7}(\mathbf{3 . 3}-\mathbf{1 3 . 3})$ \\
$\begin{array}{l}\text { Fig. 3 } \\
\text { Women vs men }\end{array}$ & $0.56(0.48-0.64)$ & $\mathbf{0 . 5 6}(\mathbf{0 . 4 9 - 0 . 6 4 )}$ \\
$\begin{array}{l}\text { Fig. 4 Women vs men } \\
\text { according to }\end{array}$ & & \\
$\quad$ Renal disease & $0.93(0.58-1.5)$ & $\mathbf{0 . 8 5}(\mathbf{0 . 5 5 - 1 . 3 )}$ \\
$\quad \begin{array}{l}\text { Pulmonary disease } \\
\text { Liver disease }\end{array}$ & $0.83(0.59-1.2)$ & $\mathbf{0 . 8 4}(\mathbf{0 . 6 1 - 1 . 2})$ \\
$\quad$ Cardiovasular disease & $0.37(0.14-0.96)$ & $\mathbf{0 . 3 6}(\mathbf{0 . 1 5 - 0 . 8 6 )}$ \\
$\quad$ Malignancy & $0.70(0.56-0.66)$ & $\mathbf{0 . 5 5}(\mathbf{0 . 4 6 - 0 . 6 6 )}$ \\
\hline
\end{tabular}

3 Department of Endocrinology, Metabolism and Diabetes, Karolinska University Hospital, Stockholm, Sweden

4 Department of Laboratory Medicine, Division of Clinical Pharmacology, Karolinska University Hospital Huddinge, Karolinska Institutet, Stockholm, Sweden

5 Department of Medicine, Karolinska University Hospital Huddinge, Karolinska Institutet, Stockholm, Sweden 